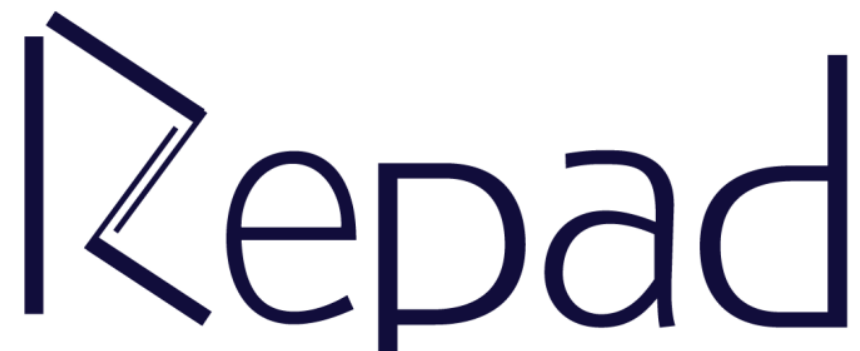

Vol. 1, N. 1 Dezembro/2017

Revista Estudos e

Pesquisas em Administração

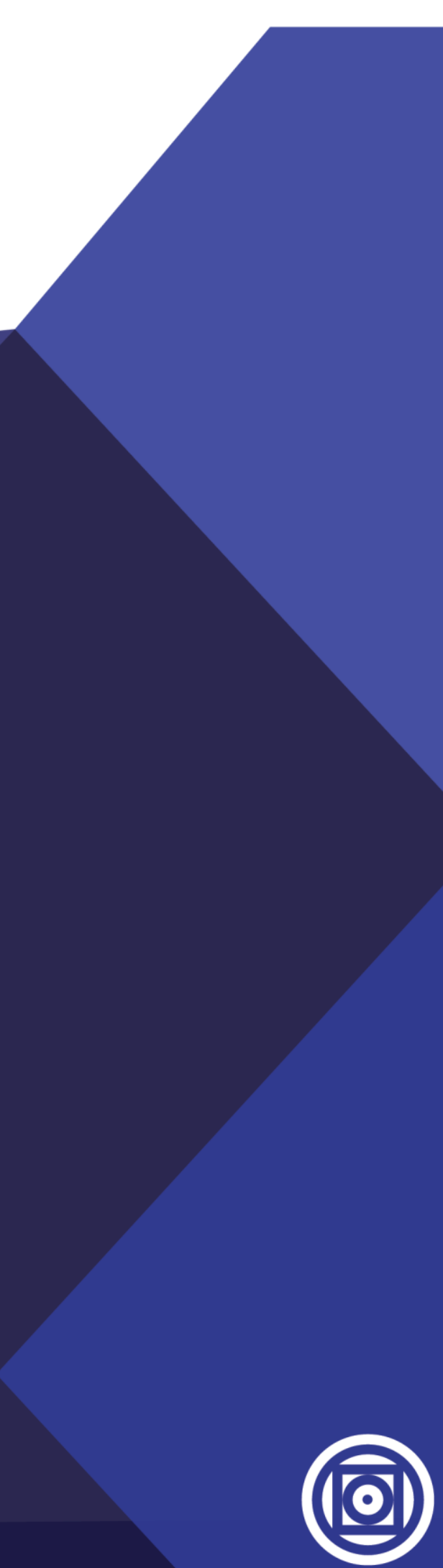




\title{
ANÁLISE SOCIOMÉTRICA: Um estudo panorâmico nas publicações do Encontro de Gestão de Pessoas e Relações de Trabalho (ENGPR)
}

\author{
Loanna Rodrigues Silva \\ Bacharel em Administração e MBA em Finanças e Controladoria pela Universidade Federal \\ de Mato Grosso \\ http://orcid.org/0000-0002-1351-9632 \\ Nathália Prochnow Nagai \\ Bacharel em Administração e MBA em Finanças e Controladoria pela Universidade Federal \\ de Mato Grosso \\ http://orcid.org/0000-0003-4863-3811
}

Lays Dantas Pereira Estudante de Administração da Universidade Federal de Mato Grosso

\section{RESUMO}

Em meio às mudanças frequentes no mercado de negócios, os vários departamentos organizacionais sofrem alterações que devem ser estudadas e aplicadas às necessidades de cada organização. A partir do estudo da teoria e de outros estudos anteriores sobre um assunto específico, os profissionais podem ter uma base fundamental de orientação para a tomada de decisões. Este estudo teve como objetivo identificar as redes sociais de cooperação entre autores, instituições, publicando artigos na questão da Gestão de Pessoas. Realizou-se uma pesquisa sociométrica em 441 artigos publicados no EnGPR, de 2007 a 2013. Assim, foi possível compreender quais tópicos foram discutidos no gerenciamento de pessoas e o nível de relacionamento entre autores e instituições de ensino superior.

Palavras chave: Estudo Sociométrico, Gestão de Pessoas, Redes de Relacionamento.

\section{SOCIOMETRIC ANALYSIS: A panoramic study in the publications of the People Management and Labor Relations Meeting (ENGPR)}

\begin{abstract}
Amid the frequent changes in the business market, the various organizational departments undergo changes that have to be studied and applied to the needs of each organization. Based on the study of theory and other previous studies regarding some specific subject, practitioners can have a fundamental basis of guidance for decision making. This study aimed to identify the social networks of cooperation between authors, institutions, by publishing articles on People Management issues. A sociometric study was conducted in 441 articles published in EnGPR from 2007 to 2013. Thus, it was possible to comprehend which topics have been discussed in people management, and the level of relationship between authors and higher education institutions.
\end{abstract}

Keywords: Sociometric Study, People Management, Social Networking. 


\section{INTRODUÇÃO}

A Gestão de Pessoas é fundamental para o sucesso de uma empresa em um mundo empresarial globalizado e competitivo. A área de Recursos Humanos de uma empresa é a principal responsável em garantir, que os funcionários possam exercer bem suas funções garantindo seus direitos e deveres, visando à satisfação plena dos funcionários e da empresa.

Estar atento às frequentes mudanças, que envolvem o mundo empresarial, é fundamental para acompanhar o mercado e se destacar diante dos concorrentes. Uma das alternativas para adquirir conhecimentos desse tipo é lendo artigos acadêmicos que servem como suporte teórico para acontecimentos reais. Ainda que cada empresa seja um caso especifico a teoria e os estudos realizados em determinada área servem como base de conhecimento, que pode auxiliar na tomada de decisão.

Este artigo baseia-se em um estudo sociométrico, e por meio deste, foi possível fazer redes sociais de autorias, de autores que escrevem juntos ou não, temas mais abordados, instituições que possuem participações nas publicações, entre outros. Por meio da análise desses dados foi possível extrair informações importantes que servem de inspiração para estudos futuros, ou para conhecer o que os autores estão publicando, quais temas tem mais destaque, quais temas são menos abordados e as respectivas relações mencionadas.

O estudo sociométrico ou de análise de redes sociais de relacionamento, como também é denominado, volta-se à exploração da matriz de relacionamentos estabelecida entre atores sociais (WALTER, 2012). Assim, foi realizado um estudo sociométrico tendo como base 441 artigos da temática de gestão de pessoas publicados no EnGPR no período de 2007 a 2013. Tendo como objetivo principal identificar as redes sociais de cooperação entre atores, compreendidos como autores e instituições, na publicação de artigos da temática de Recursos Humanos, bem como explorar os temas mais abordados.

Este artigo apresenta um referencial teórico sobre a área de recursos humanos e a importância de estudar suas temáticas. Neste tópico também é apresentada a definição do estudo sociométrico, destacando os principais conceitos e a importância de atuar em rede. Em seguida, apresenta-se a metodologia utilizada no estudo e, por fim, os resultados da análise, conclusões e as possíveis limitações/sugestões de novos estudos.

\section{REFERENCIAL TEÓRICO}

O início da área de recursos humanos foi marcado por atividades monótonas e rotineiras referentes ao ser humano, porém essas práticas foram se aprimorando e este setor deixou de ser operacional para ser um setor estratégico. Conforme Costa et al. (2011), os primeiros departamentos de recursos humanos tinham como função apenas assegurar que os procedimentos normais (admissões, demissões e pagamentos, dentre outros) fossem seguidos corretamente.

A partir da escola de Relações Humanas é que surgiu uma nova ênfase da interação entre a empresa e seus funcionários. Após as décadas de 1960 e 1970, e com o advento de novas legislações, o departamento de recursos humanos passou a oferecer especialização em áreas como recrutamento, seleção e treinamento, com um papel ainda mais abrangente (ALMEIDA, 2004). Esta área é vista como estratégica devido a sua ligação com o saber aonde a empresa quer chegar para poder contratar um profissional a altura dos anseios da corporação. 


\section{IMPORTÂNCIA DE ESTUDAR A GESTÃO DE PESSOAS}

A cada dia que passa as empresas percebem que o talento humano é um dos recursos mais valiosos, um dos grandes desafios da área de Gestão de Pessoas é gerar comprometimento do colaborador com a organização. Os avanços contínuos ocorridos nas últimas décadas têm motivado as empresas a buscarem novas formas de gestão com a finalidade de aprimorar o desempenho, alcançando resultados e atingindo a missão organizacional, somando esses fatores tem-se o pleno atendimento das necessidades dos clientes. Desta maneira, o sucesso das organizações depende do investimento nas pessoas, identificando, aproveitando e desenvolvendo o capital intelectual. (OLIVEIRA, 2011)

Uma das vantagens competitivas no mercado está representada nas pessoas que compõem as organizações, como as pessoas são diferentes e as maneiras com as quais reagem em determinados ambientes ou situações também são diferentes, o gestor tem como missão saber lidar com todos esses interstícios. Desta maneira o estudo de tudo aquilo que envolve a esfera da gestão de pessoa é extremamente importante para que os gestores saibam como agir nas diferentes situações e organizações que compõe o ambiente empresarial.

\section{ESTUDOS SOCIOMÉTRICO}

Neste estudo, empregou-se a sociometria como método de análise e revisão sistemática. Segundo Camossa e Lima (2011) a palavra sociometria significa medição do social, sendo o conjunto de técnicas para investigar, medir, estudar relações, contatos e processos vinculares que se manifestam em vários grupos sociais. A sociometria analisa atores sociais e suas relações por meio da representação de um conjunto de atores e seus vínculos (WALTER et al., 2012 apud GRANOVETTER et al., 1973).

O médico, psicólogo e filósofo Jacob Levi Moreno considerado o criador do estudo sociométrico, o define como: "um meio de medir a organização dos grupos sociais [...] é um método de pesquisa de estruturas sociais através da medida das atrações e rejeições que existem entre os membros de um grupo" (MORENO, 1999, p. 34).

Segundo Matias (2006 apud KAUFMAN, 1993), o teste sociométrico confirma a existência de alguns padrões característicos da organização dos grupos, suas expressões e configurações próprias. O estudo sociométrico é um recurso exploratório bastante indicado para estudar as estruturas sociais num dado momento ou período, com o auxílio de softwares é possível construir representações gráficas que possibilitam uma melhor análise dos dados coletados. A representação gráfica da rede social é feita por meio do sociograma, que evidencia como pontos principais: autores, laços, reciprocidades, tamanho da rede, relações e entre os dados estudados.

No que se refere à estrutura das redes, podem ser distribuídas como densas ou difusas e, relacionalmente, podem ter conexões fortes ou fracas. Essas conexões fracas e redes difusas são mais típicas nos ambientes instáveis, pois permitem maior fluxo de novas informações; já as conexões fortes e redes densas são comuns aos ambientes estáveis, já que a troca de informações é refinada, com um alto nível de confiança, cooperação, reciprocidade e controle social entre os atores (RIBEIRO, CIRANI; FREITAS, 2013 apud ROWLEY, BEHRENS; KRACKHARDT, 2000), de modo que possa conduzir ao isolamento do grupo e a uma possível dificuldade de acesso desses atores a novas informações que circulem fora daquele ambiente restrito. 


\section{PROCEDIMENTOS METODOLÓGICOS}

Para Gil (1999, p.42), a pesquisa tem um caráter pragmático, é um "processo formal e sistemático de desenvolvimento do método científico. O objetivo fundamental da pesquisa é descobrir respostas para problemas mediante o emprego de procedimentos científicos". A pesquisa é realizada quando se tem um problema e não se tem informações para solucioná-lo.

O procedimento metodológico utilizado neste trabalho consiste em uma análise sociométrica de natureza qualitativa, cujo objetivo é identificar as redes sociais de cooperação entre atores, compreendidos como autores e instituições, nas publicações de artigos da temática de Gestão de Pessoas. A população alvo deste trabalho abrange todos os artigos publicados no EnGPR, no período de 2007 a 2013, totalizando 441 artigos.

A priori foram construídas tabelas em Excel contendo informações como: nome do artigo, autores, IES, resumo, método, área temática, conclusões e ano. As informações foram extraídas todas dos artigos, exceto as IESs, onde algumas foram obtidas diretamente no artigo ou acessando o currículo Lattes do autor, ou em último caso por meio de consultas à internet.

Quanto aos dados qualitativos correspondentes, as características de cada artigo foram solidificadas para análises. Após isso, o processo de coleta e validação dos dados foram construídos gráficos e tabelas para assim realizar as análises qualitativas e sociométricas apresentadas na próxima sessão.

\section{APRESENTAÇÃO E ANÁLISE DE DADOS}

\section{ANÁLISE QUALITATIVA}

Nesta fase da pesquisa são analisadas as características dos artigos em termos de abordagem de pesquisa, métodos utilizados, áreas temáticas, autores e suas produções, e IES e suas representatividades.

A Figura 1 indica a abordagem de pesquisa e os principais métodos utilizados nos artigos analisados. Partindo de uma amostra de 441 artigos analisados, podemos observar que quanto ao método de pesquisa utilizado o que mais se sobrepõe em todos os períodos é o qualitativo que se mantém em alta nos quatro anos de publicação correspondendo a mais da metade. Outra abordagem bastante utilizada foi à quantitativa que teve uma representatividade também significante em todos os períodos. As abordagens classificadas como quali-quanti e ensaio teórico tiveram uma representatividade parecida, tendo um crescente no ano de 2011, mas mantiveram-se no mesmo nível no ano de 2013.

No tocante às abordagens temáticas, pode-se destacar sete temas mais utilizados, enquanto alguns temas obtiveram significativo crescimento, como o comportamento organizacional que representou $14 \%$ em 2007 e em 2013 chegou a $25 \%$, houve temas que diminuíram seu grau de participação, como relações de trabalho que representava 15\% em 2007 e em 2013 caiu para 7\%. No total, o tema que alcançou um número maior de publicações nos quatro períodos foi sentimentos no trabalho. A Figura 2 apresenta esses dados. 
Figura 1: Gráfico dos métodos utilizados

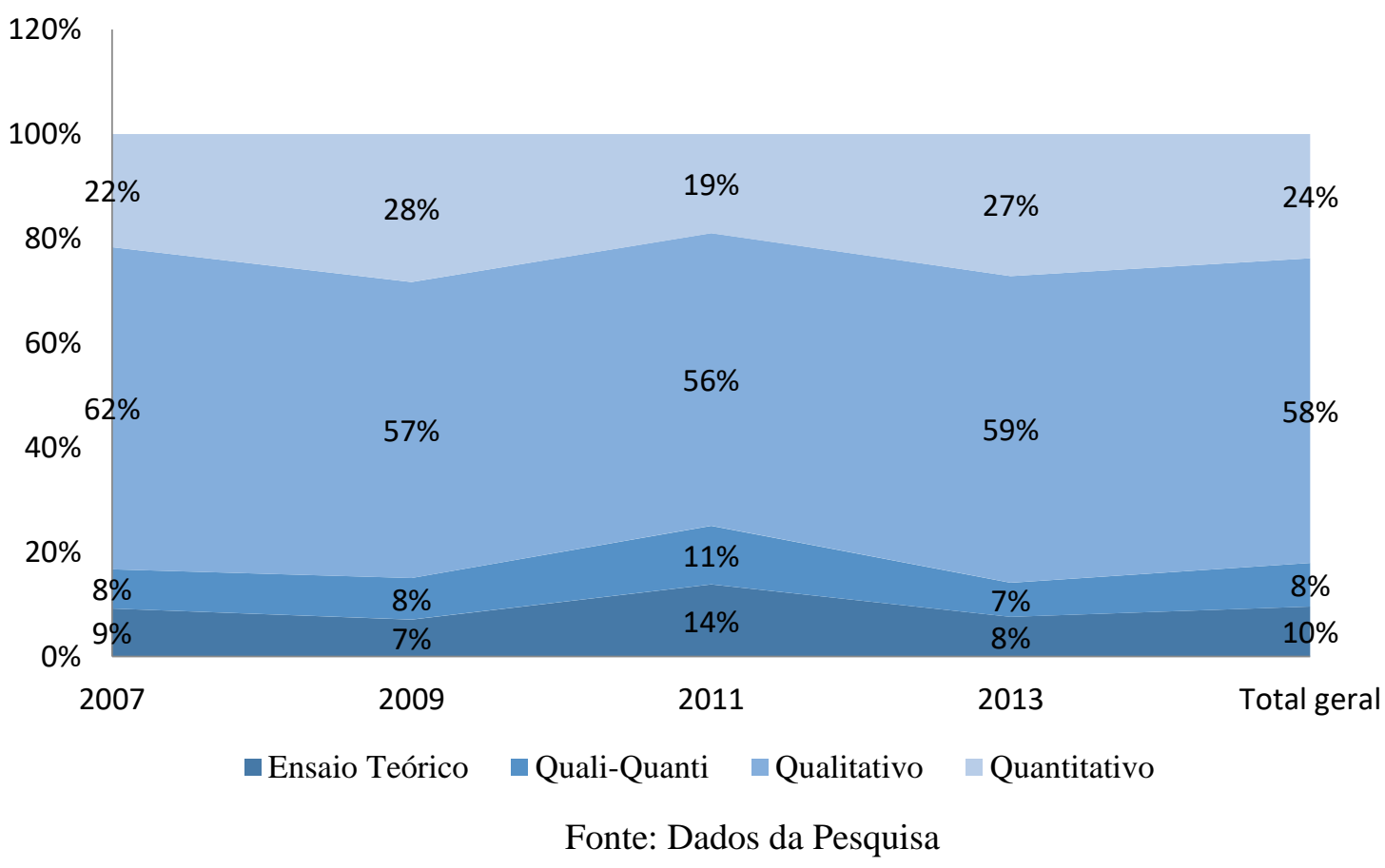

Figura 2: Gráfico da evolução dos principais temas

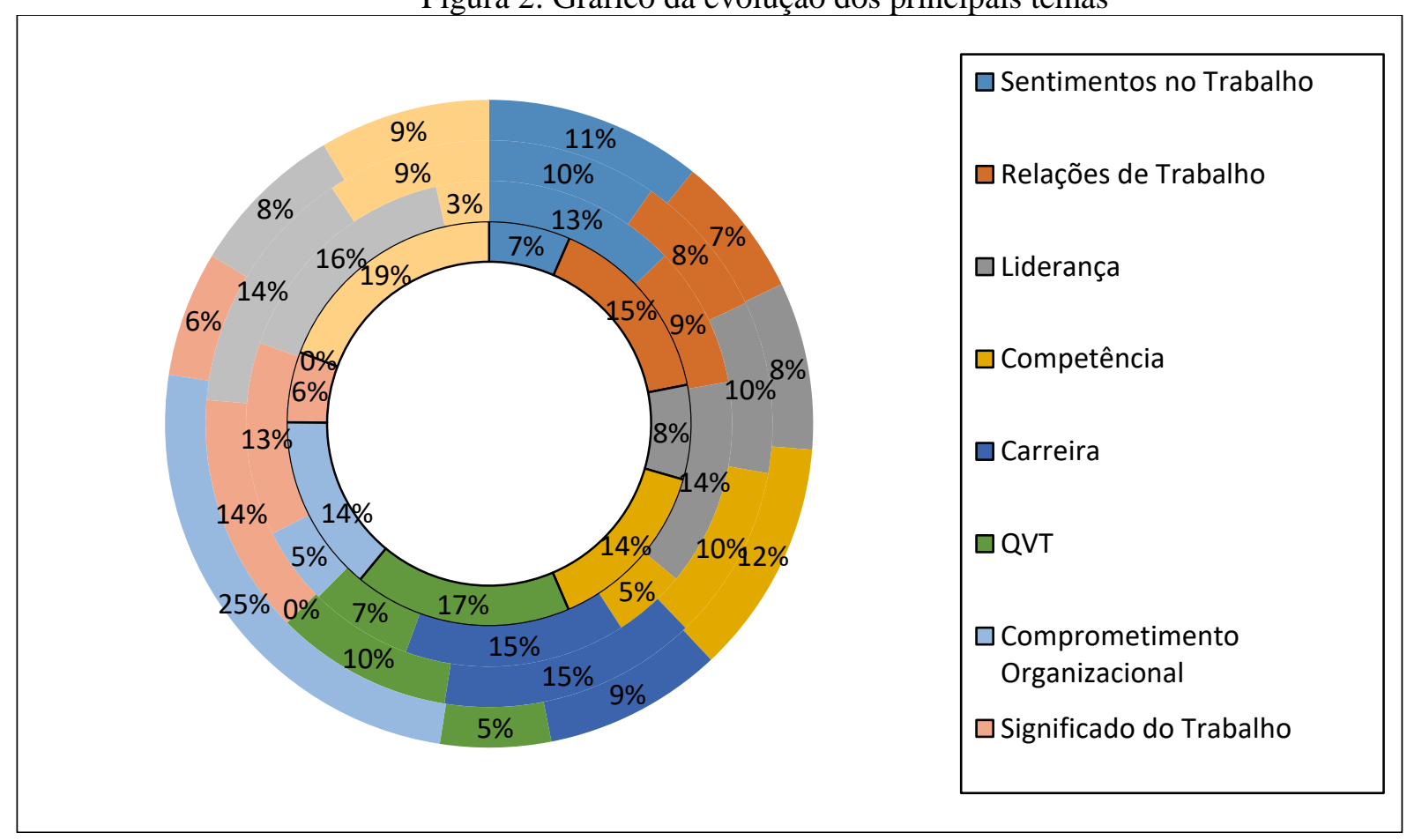

Fonte: Dados da Pesquisa

A Figura 3 apresenta os autores com maior número de publicações. É possível notar que André Luiz Fischer da USP, foi o autor que mais produziu nesta esfera de quatro períodos, 
totalizando nove publicações. Também merece destaque a autora Vera L. Cançado da FIPEL com oito publicações e Antônio Carvalho Neto da University of Stuttgart com sete publicações. É importante ressaltar que desses autores que obtiverem mais publicações quatro são da USP, mostrando sua grande representatividade no congresso.

Figura 3: Gráfico dos autores mais profícuos e suas instituições

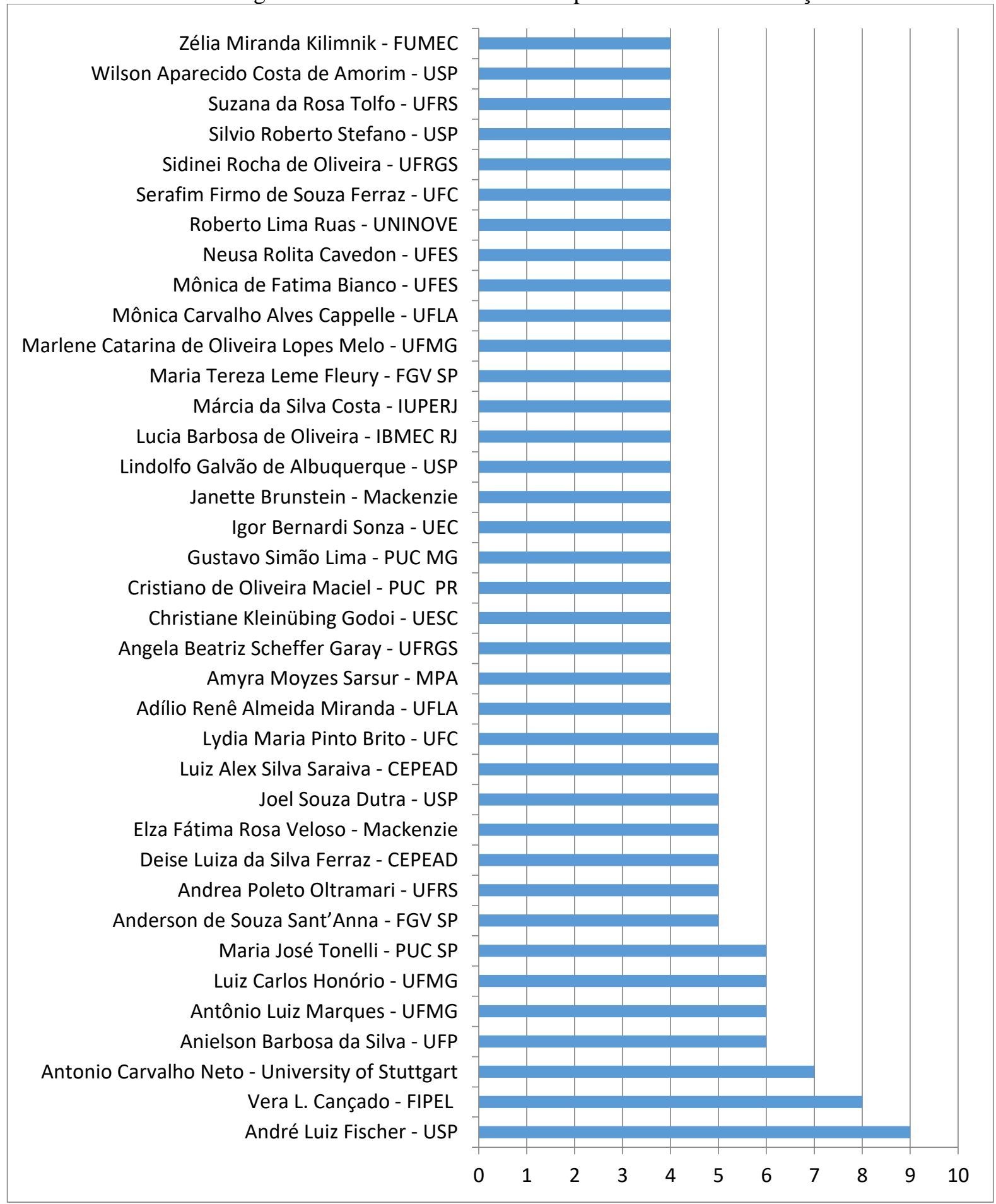

Fonte: Dados da Pesquisa 
Em relação à análise das instituições que são mais representadas, nestas quatro edições do EnGPR, as IES que mais se destacam são UFMG, USP, UFRS, UFLA, PUC MG, e FGV, que representam metade do total de publicações das principais instituições que possuem maior representatividade no congresso. Após a análise dos dados qualitativos, busca-se compreender a formação de redes de atores por meio da análise sociométrica. Conforme dados da Figura 4.

Figura 4: Gráfico das principais instituições de coprodução

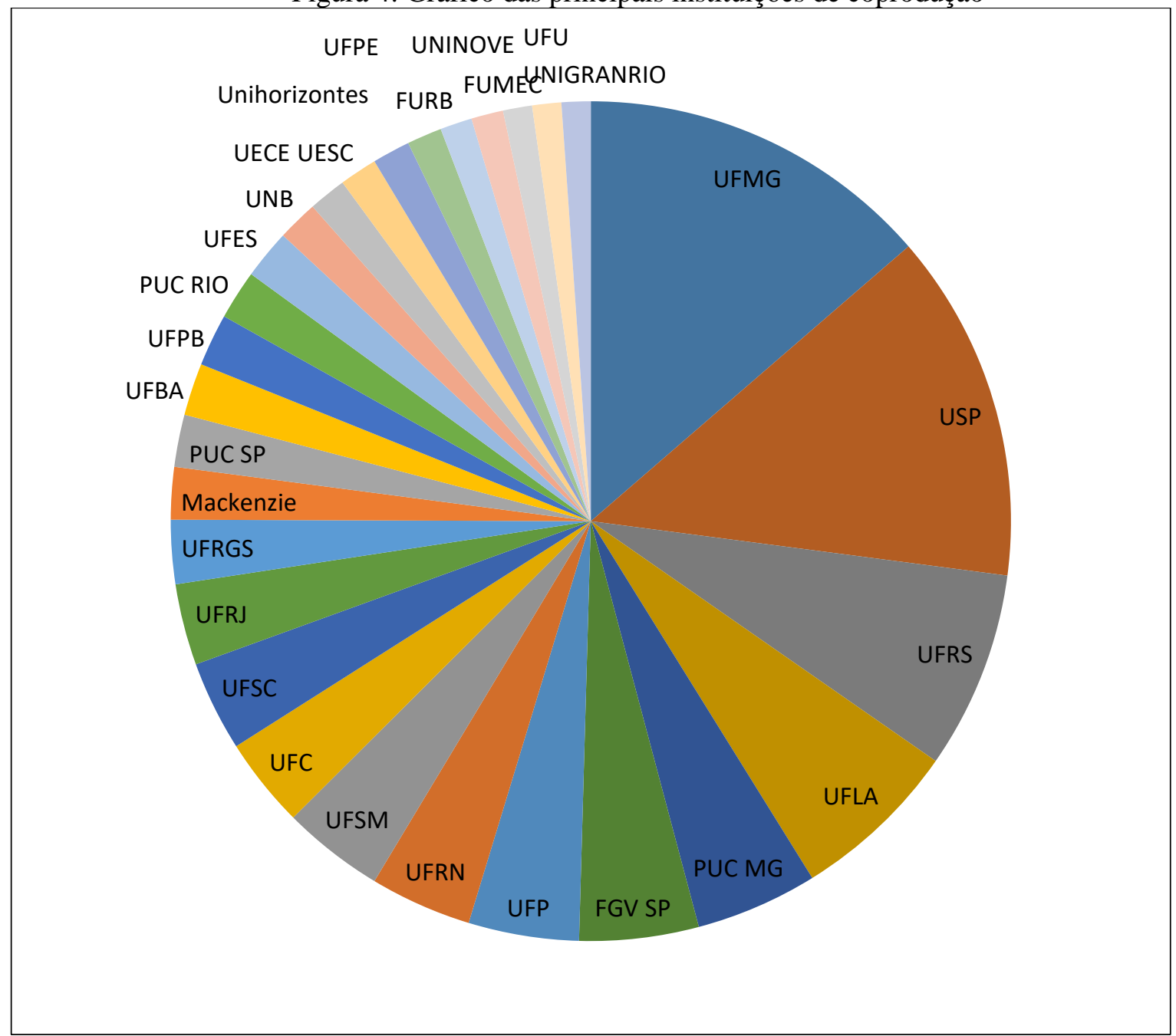

Fontes: Dados da Pesquisa

\section{ANÁLISE SOCIOMÉTRICA}

O estudo sociométrico possibilita a identificação de redes sociais de cooperação entre atores. Desta forma, é possível observar quais autores são intermediadores entre as redes de construção de conhecimento. Na Figura 5 estão apresentadas as principais redes formadas no ano de 2007. Observa-se que Leonardo Flach, com 3 artigos publicados, e André Luiz Fischer, com 2 artigos, desempenham papéis centrais na rede, ou seja, são os principais intermediadores de conhecimento entre diversos autores, alcançando também um maior número dos mesmos.

Conforme a Figura 6, onde está apresentado o mapa de autoria do ano de 2009, observase que há a criação de novas redes de autoria com novos autores não presentes anteriormente. 
Neste ano, André Luiz Fischer desempenha um significativo papel na intermediação de redes, pois apresenta vínculo com outros oito autores, que por sua vez o conecta com outros diferentes grupos. Outros nomes que apresentam um importante papel de intermediação são, Carla Fernanda de Lima, com 3 publicações, Adílio Renê Almeida Miranda, com 2 publicações e Betania Tanure com 1 publicação.

Figura 5: Mapa de Coautoria no Ano de 2007

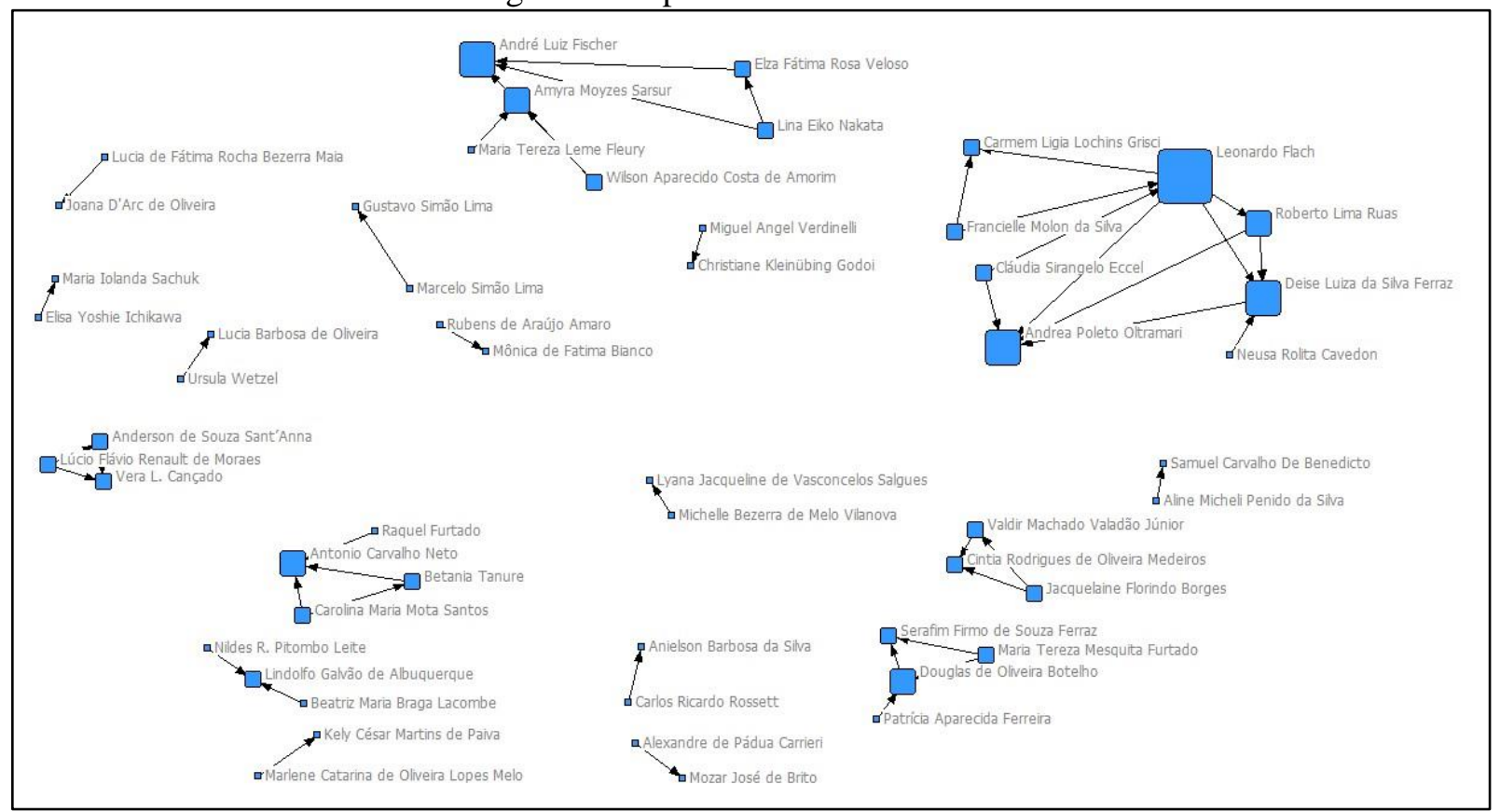

Fonte: Dados da Pesquisa

Figura 6: Mapa de Coautoria no Ano de 2009

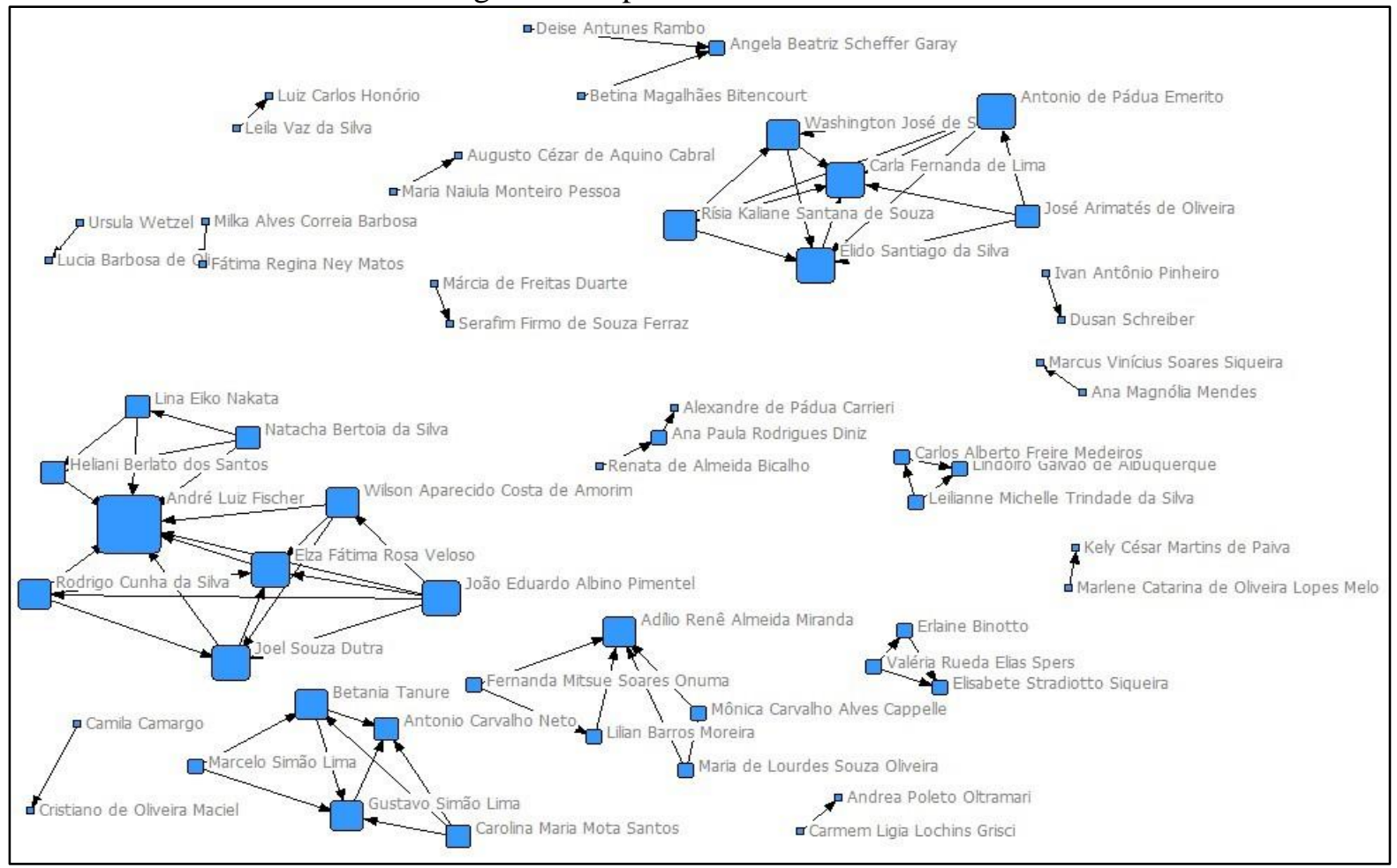


Fonte: Dados da Pesquisa

Para a construção do mapa de coautoria do ano de 2011 demonstrado na Figura 7, foram desconsiderados os vínculos de primeiro grau. Há um maior número de redes em relação aos anos anteriores, e os principais intermediadores identificados são, Antônio Luiz Marques com 2 publicações, Adílio Renê Almeida Miranda também com 2 publicações e André Luiz Fischer com 1 publicação. Percebe-se que há um aumento de coautorias por artigo, desta maneira um número maior de autores é alcançado pela rede.

Figura 7: Mapa de Coautoria no Ano de 2011

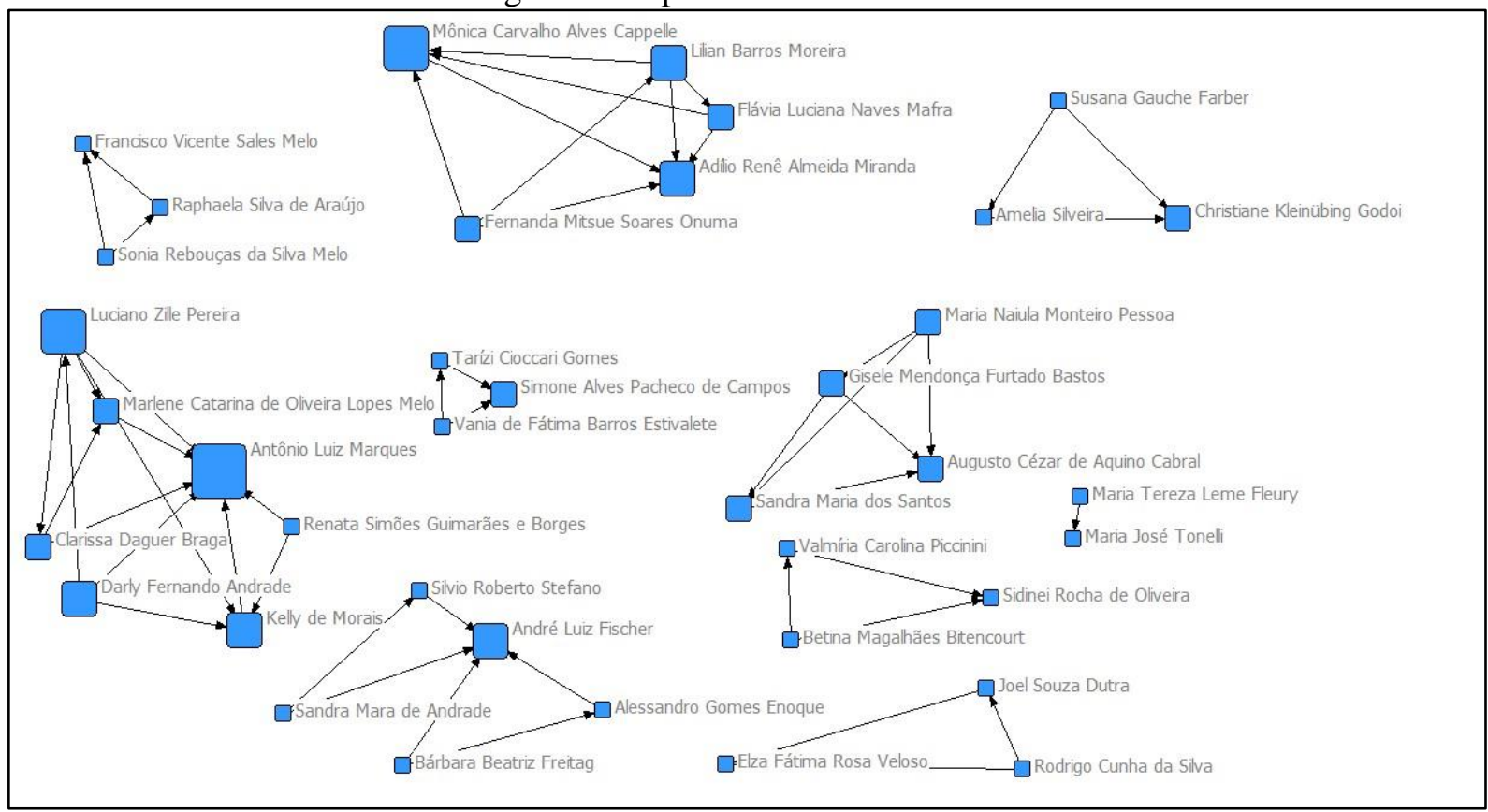

Os principais intermediadores das redes em 2013 estão apresentados na Figura 8.

Percebe-se que o autor André Luiz Fischer que nos períodos anteriores desempenhava um destacado papel de intermediação, no ano de 2013 não teve participação nas principais redes de conhecimento criadas entre os autores. Neste ano, os principais intermediadores foram Elza Fátima Rosa Veloso com 1 publicação e Marcelo da Silva com 3 publicações.

Nos quatro períodos analisados, 2007, 2009, 2011 e 2013, observa-se que há diversas redes de conhecimento criadas, tanto grandes quanto pequenas. Mas todas se encontram isoladas, não há um autor chave que conecte uma rede a outra. Dessa forma o conhecimento não é compartilhado entre as diferentes redes existentes. 
Figura 8: Mapa de Coautoria no Ano de 2013

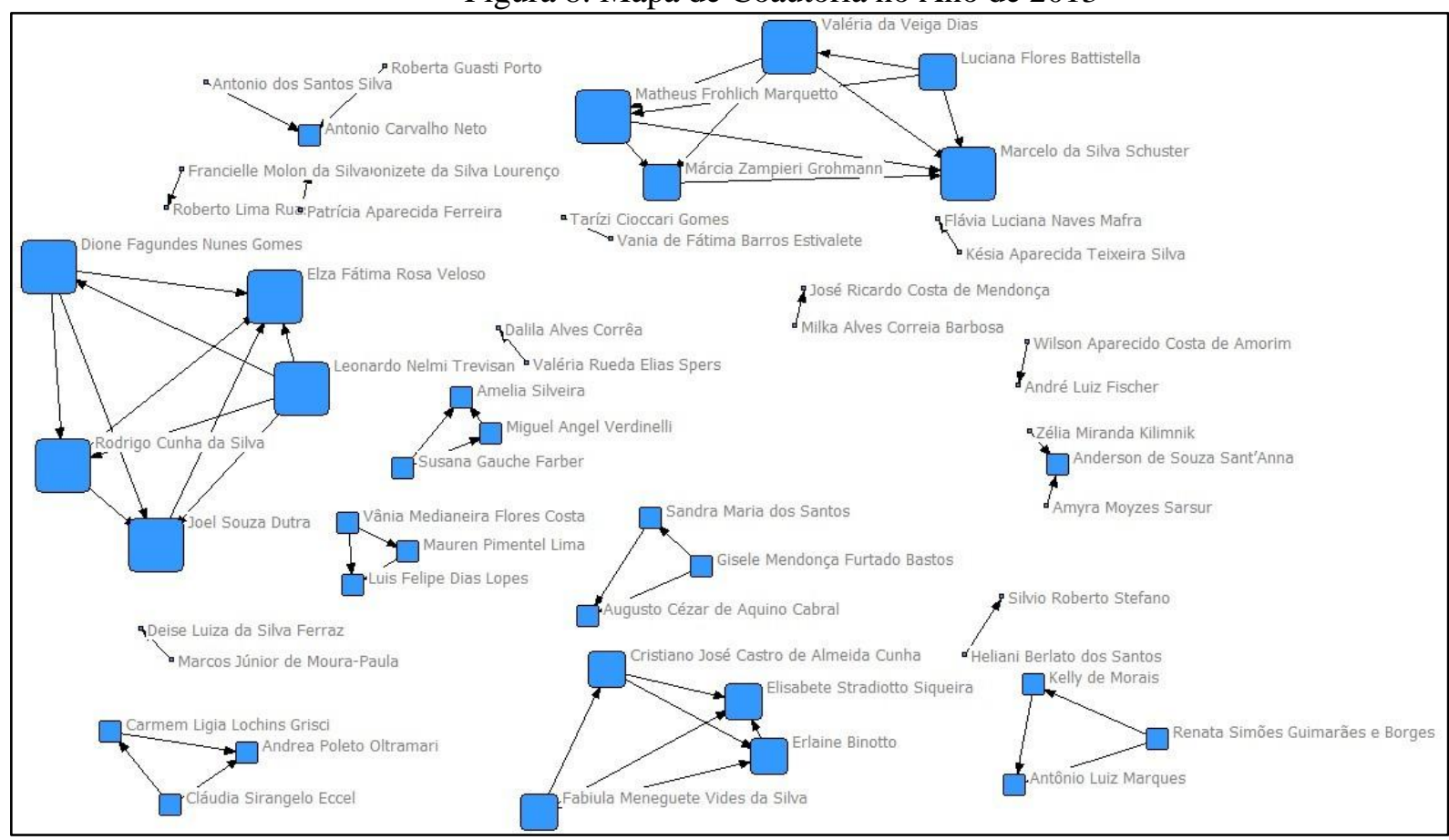

Fonte: Dados da Pesquisa

As Figuras 9 e 10 apresentam o mapa de coprodução das instituições de ensino no ano de 2007 e 2009 respectivamente.

Figura 9: Mapa de Coprodução das IES no Ano de 2007

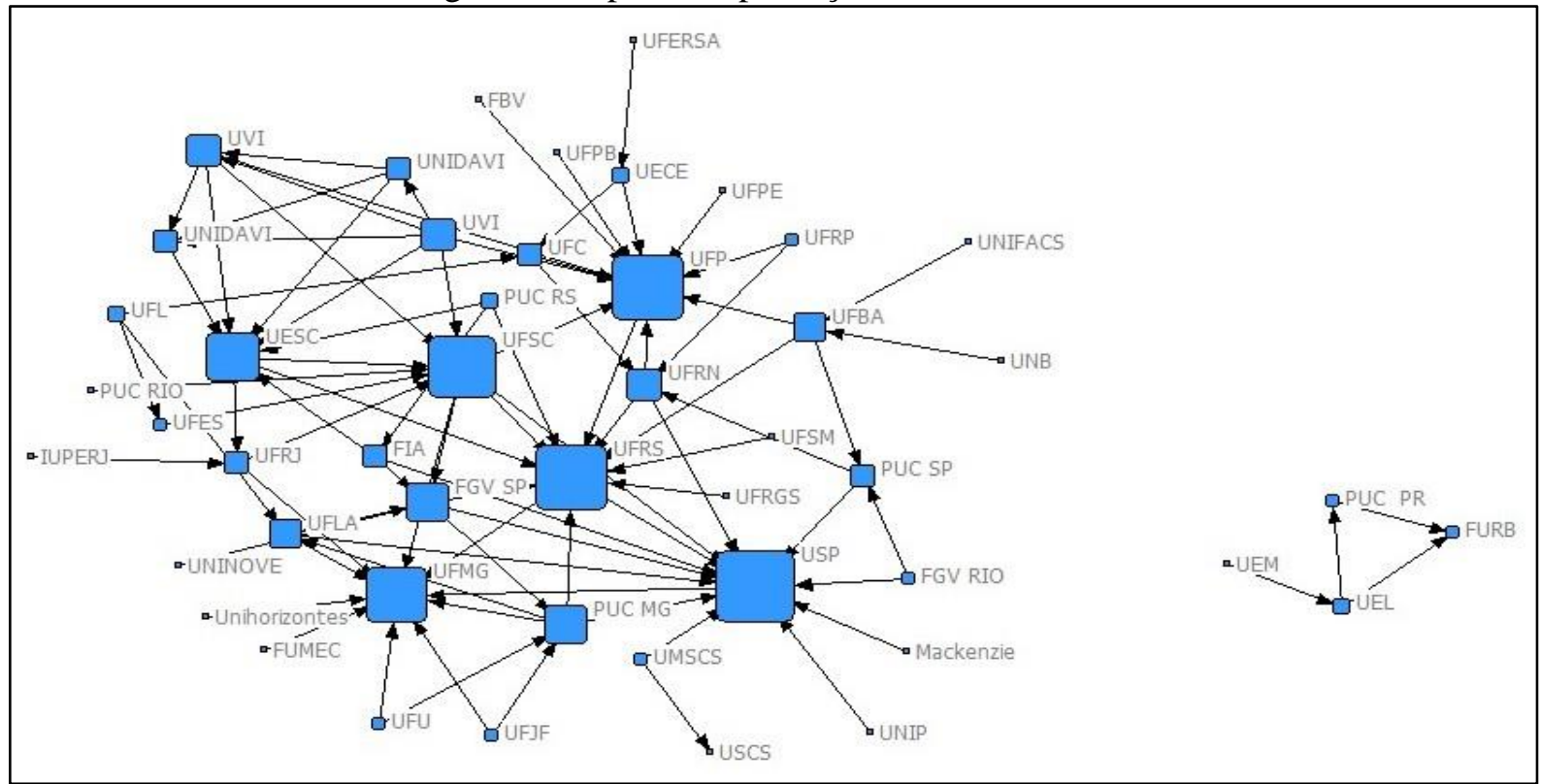

Fonte: Dados da Pesquisa 
Figura 10: Mapa de Coprodução das IES no Ano de 2009

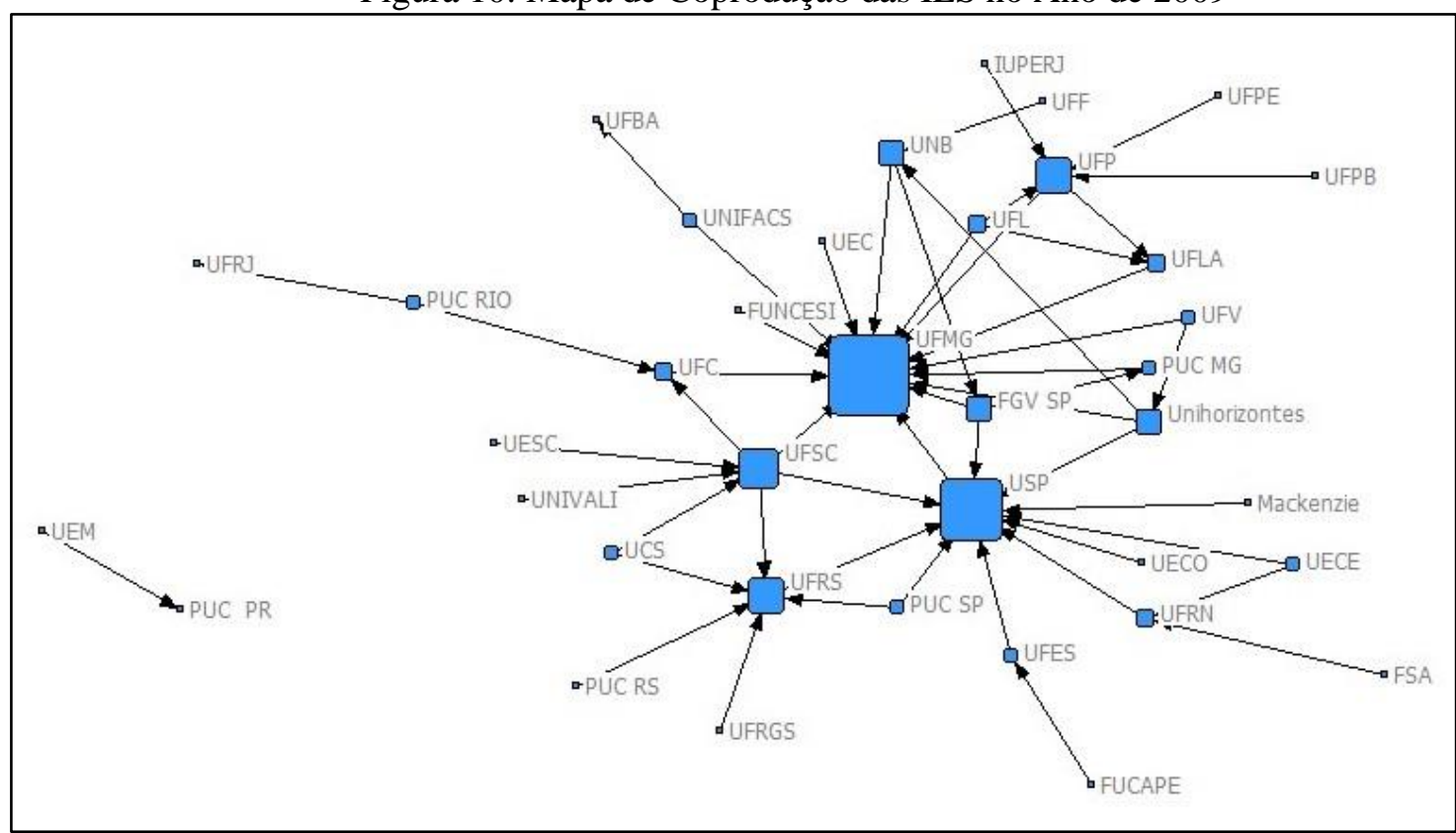

Fonte: Dados da Pesquisa

As instituições que apresentam papel central na rede são USP, UFP, UFRS, UFSC e UFMG e mantém essa colocação em ambos os anos. Interessante notar que as IES são de diferentes regiões do país o que mostra uma rica troca de conhecimento onde autores são alcançados em diversas partes do Brasil. Nota-se a presença de uma pequena rede formada na região sul do país, onde a maior difusão do conhecimento não é possibilitada. No ano de 2009 há a diminuição na participação do número das instituições na construção das redes de conhecimento.

Conforme a Figura 11, é possível observar no mapa de coprodução do ano de 2011, que as instituições que intermediam as redes de conhecimento foram USP, UFMG, e há novos nomes como, UFF e FGV SP. Também há pequenas redes em crescimento que são intermediadas por UFLA e UFPB.

É interessante notar, conforme a Figura 12, que há uma diminuição no tamanho da rede principal de difusão do conhecimento, onde as instituições intermediadoras são USP, UFMG e UFLA. Por outro lado, surge uma rede com a grande parte das instituições vindas do sul do país, que é intermediada principalmente pela Uninove.

Nota-se que ao longo do tempo o tamanho da rede principal de conhecimento diminuiu e há um aumento de redes isoladas em uma única região. Desta forma, observa-se que a propagação do conhecimento fica isolada, não é trocada entre diferentes regiões e instituições do país, o que leva a criação do conhecimento ficar limitada. 
Figura 11: Mapa de Coprodução das IES no Ano de 2011

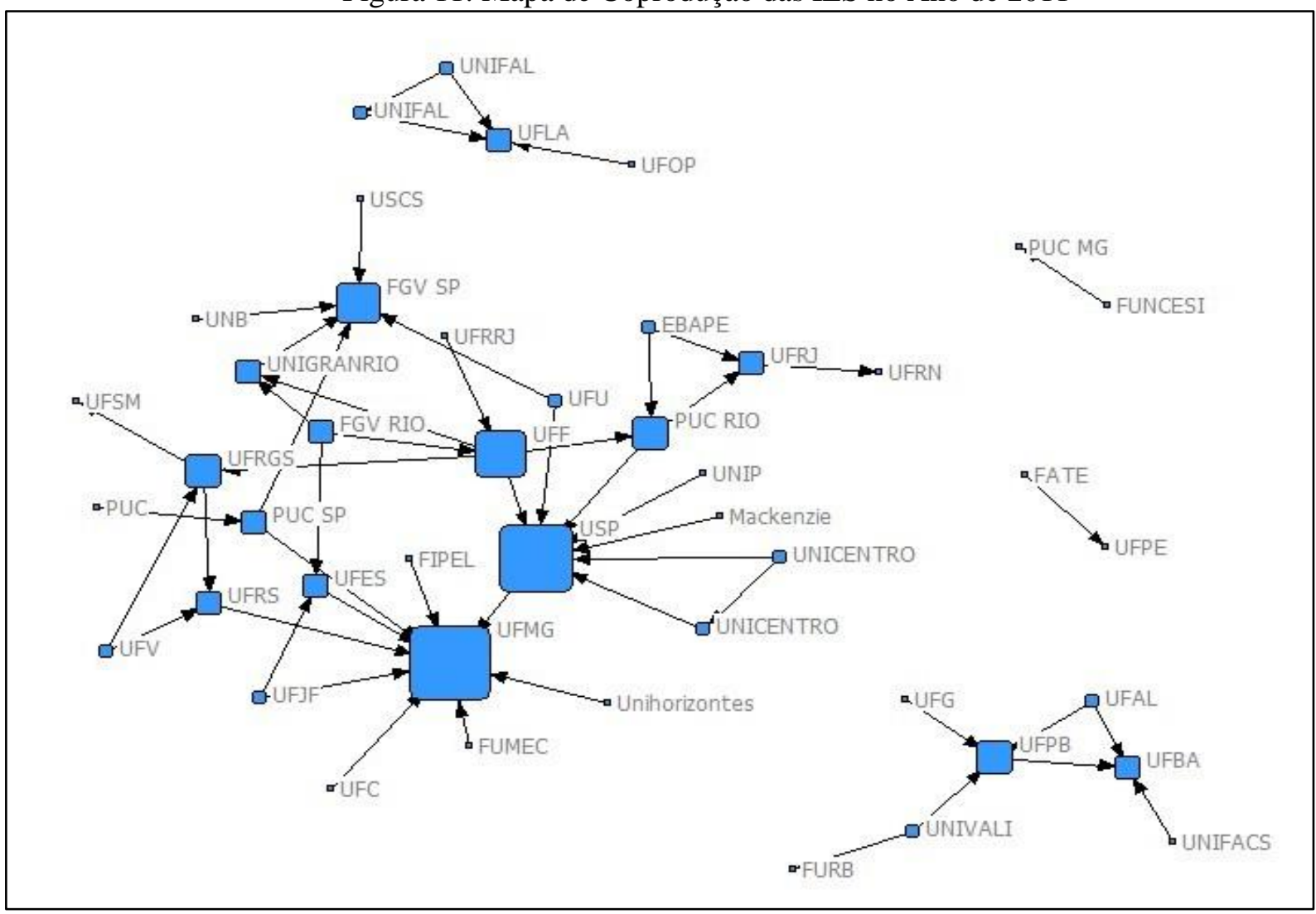

Fonte: Dados da Pesquisa

Figura 12: Mapa de Coprodução das IES no Ano de 2013

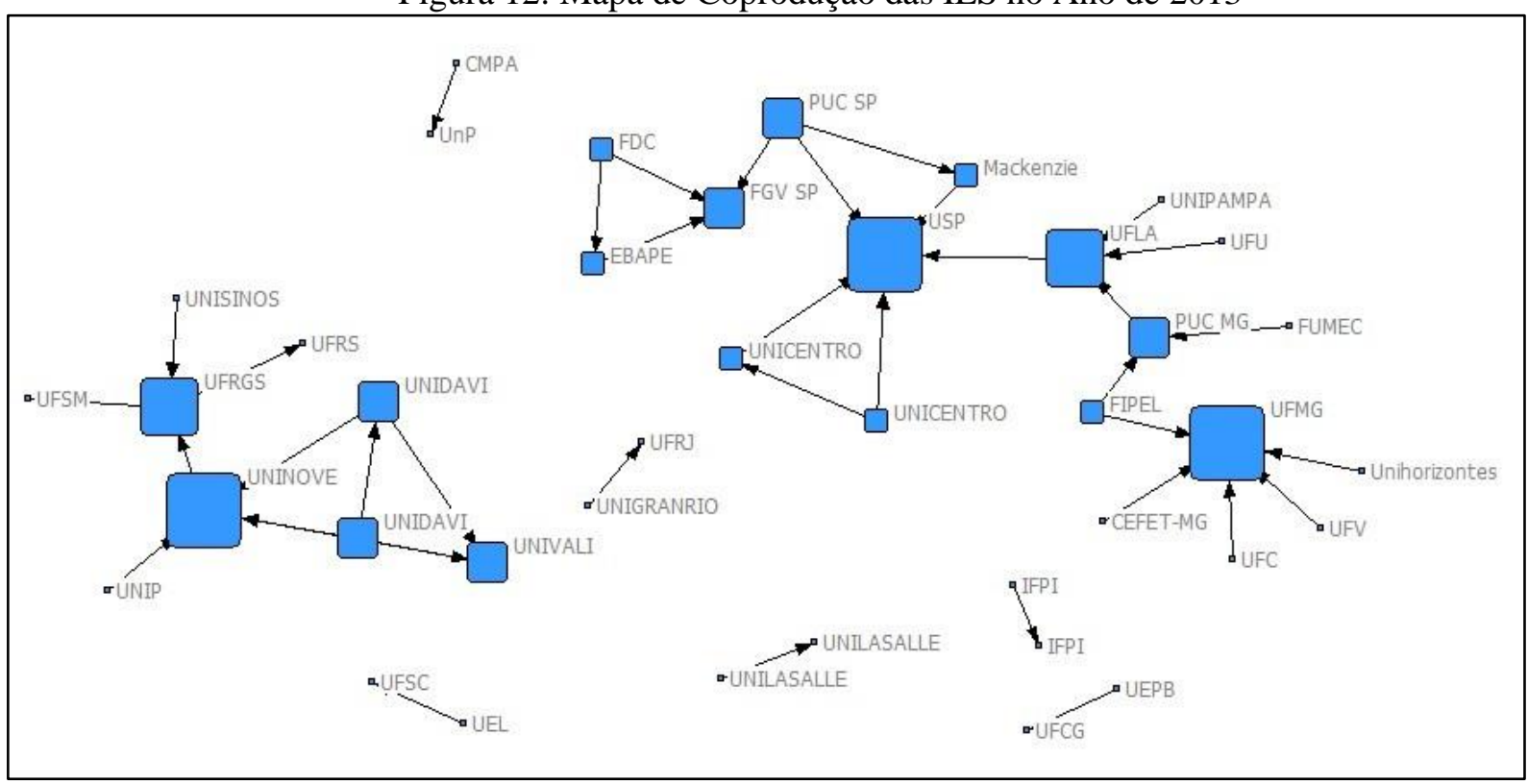

Fonte: Dados da Pesquisa 


\section{REFLEXÕES FINAIS}

O processo de globalização, principalmente na esfera empresarial fez com que mudanças fossem adotadas na gestão administrativa das empresas. Essas mudanças se referem principalmente ao modo de encarar as pessoas que as compõem. Diante disso é importante que se realizem estudos constantes sobre esta área, que é de extrema importância para qualquer organização.

Por meio de um estudo sociométrico e análises qualitativas realizadas com a amostra de 441 artigos publicados no congresso EnGPR nos anos de 2007, 2009, 2011 e 2013 foi possível a identificação de tendências e redes de criação de conhecimento. Este trabalho identificou as principais instituições de ensino, autores, temáticas, métodos de pesquisa utilizados no congresso.

Apesar da riqueza desta pesquisa que possibilita uma visão geral de todos os artigos da temática de gestão de pessoa a publicados no congresso, a dificuldades em trabalhar os dados são intensas, visto que o número de dados é muito grande, e em alguns artigos as informações não são estão apresentadas claramente, obrigando a realização de uma leitura mais detalhada.

A partir deste estudo é possível desenvolver novas pesquisas, com o intuito de responder o porquê os tais temas aqui indicados estão sendo os mais abordados, quais outros temas importantes ainda não estão sendo discutidos, bem como a participação das IES na construção desse conhecimento, e em contraponto o motivo da ausência de muitas das outras existentes no país.

\section{REFERÊNCIAS}

ALMEIDA, F. A. Gestão de Recursos Humanos. Vida Econômica Editorial, 2004.

CAMOSSA, D. A.; LIMA, N. S. T. O psicodrama e sua contribuição para a saúde mental. Revista de Ciências da Educação, Americana, v. 25, n. 8, p.1-12, jul./dez. 2011.

COSTA, F. J.; LEONEL, F. R. P.; OLIVEIRA, G. L. A Área de Recursos Humanos e o Interesse Profissional dos Estudantes de Administração. Revista Pretexto v. 12, n. 3 - julho/setembro 2011.

GIL, A. C. Métodos e técnicas de pesquisa social. São Paulo: Atlas, 1999.

MATIAS, D. P. Abuso Sexual e Sociometria: Um Estudo dos Vínculos Afetivos em Famílias Incestuosas. Psicol. estud. [online], vol.11, n.2, p. 295-304. 2006.

MORENO, J. L. Psicoterapia de Grupo e Psicodrama. Campinas: Editora Livro Plena, Versão online. 1999.

RIBEIRO, H. C. M; CIRANI, C. B. S.; FREITAS, E. J. Análise da produção científica da revista de administração e inovação. Revista de Administração e Inovação. v. 10, n. 4, p. 208-228, 2013.

OLIVEIRA, R. F. L. Gestão Estratégica de Pessoas - uma Ferramenta Poderosa. IV Encontro de Gestão de Pessoas e Relações de Trabalho. EnGPR. Brasília. 3 a 5 de 2011. 
WALTER, S. A.; BACH, T. M.; BARBOSA, F. Estrutura das Redes Sociais e Bibliometria: Uma análise longitudinal da Abordagem de Estratégia como Prática. EnAMPAD. Rio de janeiro. 2012. 